\title{
VIDEO LAB REPORTS USING TikTok APPLICATION FOR INORGANIC CHEMISTRY CLASS AT THE FLEXIBLE DIGITAL MODEL FDM AT PREPATEC MORELIA
}

\author{
Audiffred_Hinojosa A \\ ITESM Campus Morelia, México
}

\begin{abstract}
At PrepaTec Morelia, the subject of inorganic chemistry is taught at the third semester of High School, five days a week in 50-minute sessions. Last year we had 129 students' ages between 16 and 17 years distributed in 4 groups taking the class. Due to the contingency of Covid-19, the class was redesigned to adapt to the virtual model. As part of the class in the face-to-face model, several laboratory practices related to the topics of the course are carried out and the idea was to redesign them as well to the virtual model. Therefore, it was thought of activities that promote the interest of the students so that they develop scientific competencies using technology; after reading the article on the use of TikTok in the classroom, it was decided to use this tool. The idea was to find two fun activities for the students to do at home and to comply with showing a chemical phenomenon and instead of making a written report they were asked to make a video using the TikTok app so that the students would present the conclusions and explanation of these observed phenomena. The two activities that were chosen were: Intermolecular Forces: Magic Trick and Hot Ice with sodium bicarbonate, At the end of the activity the results of the satisfaction survey with grades of 4.76 were obtained with a standard deviation of 0.28 and students seem to be more motivated by doing a video report rather than filling a document with the lab results.
\end{abstract}

Keywords: Tiktok, Chemistry, Labs, Virtual Education, Educational Innovation, Higher Education

\section{Introduction}

In PrepaTec Campus Morelia the subject of inorganic chemistry PC3014 Matter and the environment (see image 1) is taught in the third semester, five days a week in 50-minute sessions. 


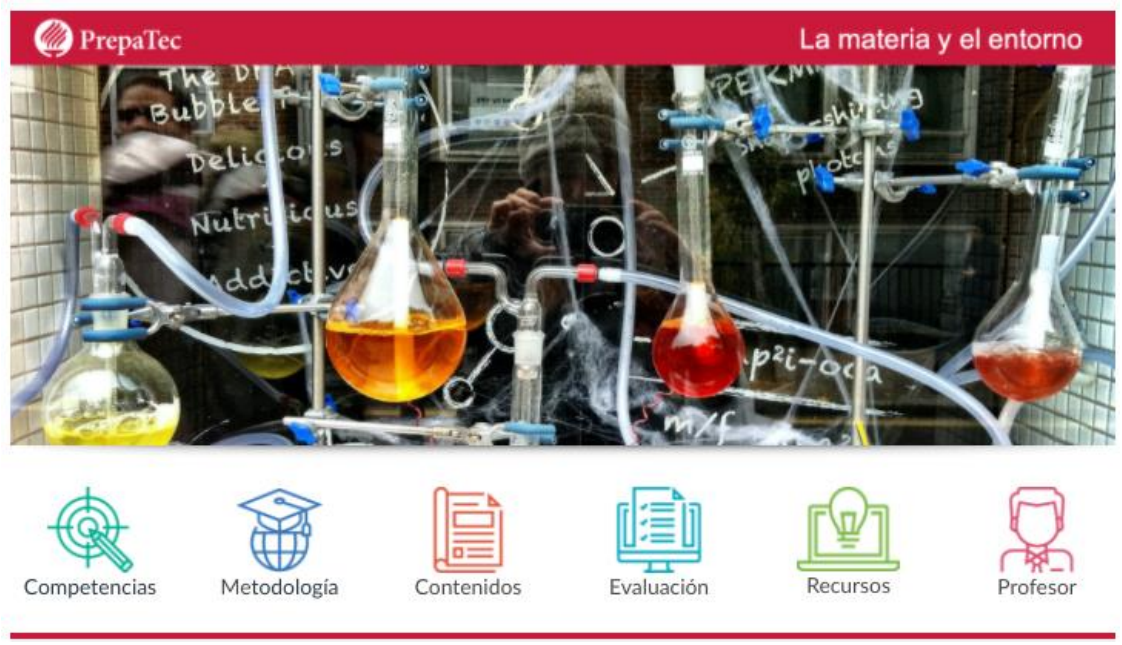

Image 1 Cover of the class PC3014 The subject and the environment

DR @ Instituto Tecnológico y de Estudios Superiores de Monterrey, México

There were at the time 129 students taking the class of inorganic chemistry at the January- May 2021 semester at the HighSchool (Bachillerato). The ages of the students were between 16 and 17 years (see graph 1), distributed in 4 groups.

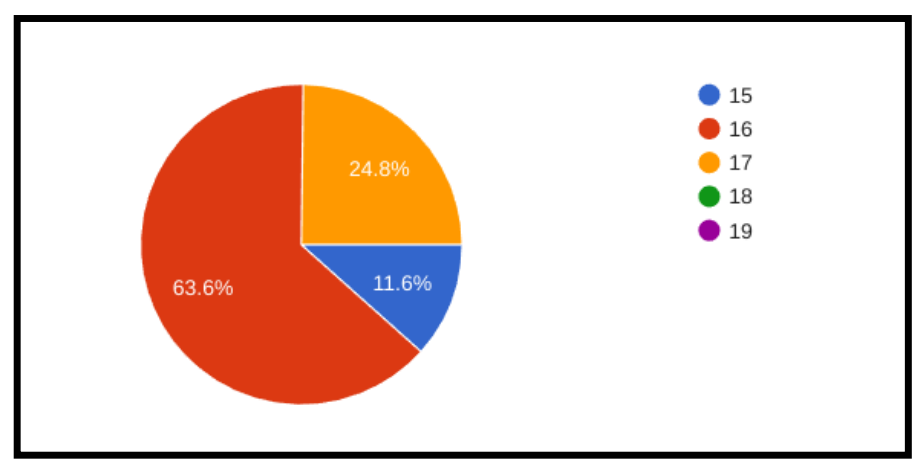

Graph 1: Age of the 129 students taking the class Matter and the environment January-May 2021

Due to the contingency of Covid-19, the class Matter and the Environment had to be redesigned to adapt to the virtual model that was called Flexible Digital Model (MDF 2021). By using zoom for video conferencing and adjusting the session into synchronous and asynchronous. The course was redesigned in order for the teacher to explain the key concepts of the topics and carry out activities that reinforce the student's learning during the synchronous session. Asynchronously, the student will work on the development of competencies through weekly investigations and activities that allow them to relate the topics seen in class with real applications.( see Table 1)

\section{Table 1: Teaching approach for the Flexible Digital Model}

Synchronous

Per week: 5-6 synchronous hours

Synchronous Digital: Teacher and Student in the same digital space (webconference).

\section{Asynchronous}

Per week: 3-5 asynchronous hours for the work of the weekly integrative activity.

Asynchronous / online: The activities and materials are available on the platform for the students to work on their own 
Following the educational model Prepa Tec21, this course has been designed under an online format with which self-management skills and use of technologies are encouraged. The online model emphasizes the following elements: collaboration, use of technology, flexibility of time and flexibility of space. (Tec21 2020)

\section{Labs on the virtual educational model}

As part of the class in the face-to-face model, several laboratory practices related to the topics of the course are carried out during each semester, two for each partial. Students had to attend lab practice as a regular class and submit a written report with the observations, results and conclusion. Lab work and lab reports accounts for $15 \%$ of their grade. (see table 2)

Table 2: Grading for the class PC3014 Matter and the environment

\begin{tabular}{lc}
\hline Listing & $\%$ \\
\hline Class Activities & 25 \\
Labs & 15 \\
Key Activity & 10 \\
Quizzes & 10 \\
Exam & 40 \\
\hline Total & 100
\end{tabular}

The lab dynamic had to be also modified at the Flexible Digital Model to be able to be carried out by the students from home as an asynchronous activity or in an online lab or simulator on an synchronous activity.

Therefore, it was thought of activities that promote the interest of the students so that they develop skills that are useful to them, activities that stimulate their interests, their environment and that, given the circumstances due to the Covid-19 contingency, put skills in function using technology in a fun way, In a first moment we study the idea of using simulator in order to study the chemical phenomena (MDF 2021)

It was consulted several sources especially one project performed in our same school PrepaTec Morelia by Professor María del Pilar Ponce Cincire with the title Science Laboratories at Home in which she discover that student had a preference of doing experiments at their house that using an online lab or a simulator to the question: If the classes stay on virtual mode, Will you like to use a lab simulator or would you like to keep doing the experiments at home? From a total of 77 students 98.7\% answered that they would like to keep doing the experiment at home and only $1.3 \%$ answer that they would rather use a lab simulator. (See graph 2).

According to the results, students like to do the experiments at home because this gives them the opportunity to be away from the computer for some time, especially after taking all their classes online in front of a computer. Students also seem to like hands-on activities and the possibility to make these experiments with some members of the family while they have to be home because of the pandemic (Ponce_Cincire 2021) taking all this into account it was decided to request their student taking the inorganic chemistry class to do the lab experiment at home. 


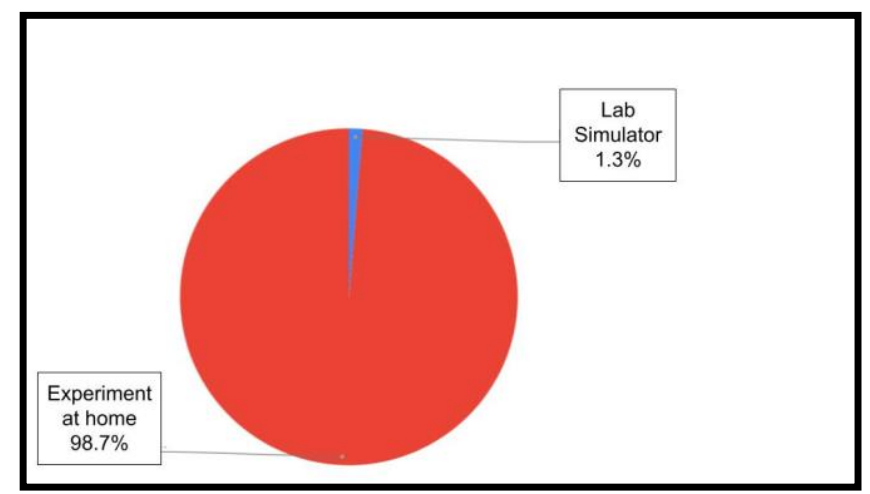

Graph 2: Answer of 77 students to the equation If the classes stay on virtual mode, would you like to use a lab simulator or would you like to keep doing the experiments at home? $1.30 \%$ preferred the use of a lab simulator and $98.70 \%$ preferred to keep doing the experiments at home (Ponce_Cincire 2021)

After making this decision it was have to be decided if the students will continue making a written lab reporter it was a good idea to find another method for them to deliver their results and their conclusions and the use of a social network application seem a good approach to both introduce technology to the class and make it more flexible.

The students were asked what Social Network do you like using the best? Obtaining as a result that number one network was instagram with more than $51.9 \%$ preference followed by TikTok with $14.7 \%$ preference (see graph 3 ).

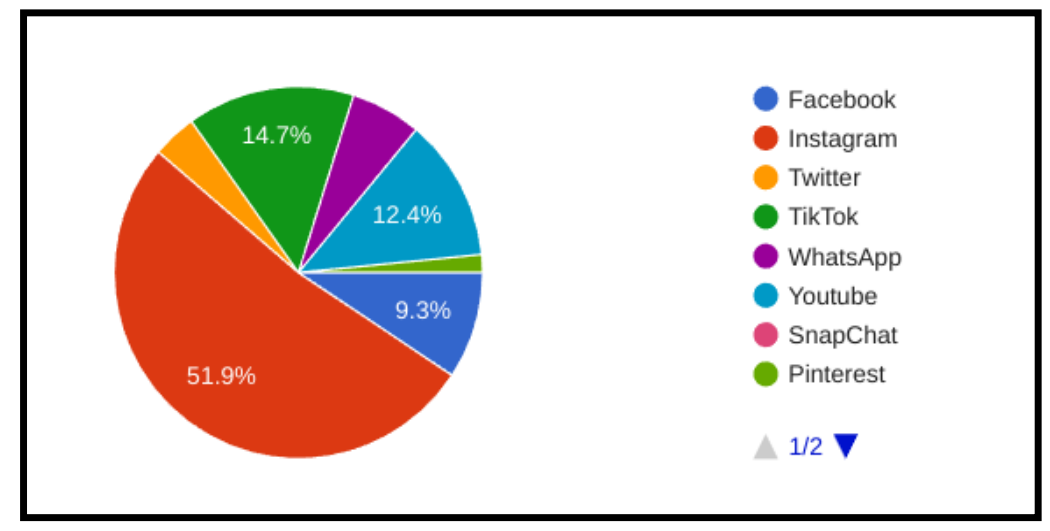

Graph 3: Preference of students for different social networks applications

We looked at both networks and their functionalities, although students had preference over instagram application but one disadvantage we found is that once a story is created, customisable and post only lasts 24 hour available for users to see, also users publish more mobile photography than stories.(Miles 2013).

After reading the article on the use of TikTok in the classroom by Professor Fernando Pantoja Bedolla, it was decided to use this tool, finding it more suitable for our project. This application allows you to make a customized one minute video, to share it with friends, and to download it as a mp4 format in order to share on other platforms. (Pantoja_Bedolla 2021)

TikTok, known in China as Douyin, is a video-sharing social network application made to share videos. This platform is used to produce videos that have a duration from fifteen seconds to one minute. Some important data about TikTok is that it has reached over 2 billion downloads by April 
$2020,41 \%$ of its users are between the ages of 16 and 24 and among these TikTok users, 90\% say they use the app daily (Anderson 2020).

Looking at the TikTok platform the TikTok channel of Dr Phillip Cook High School Chemistry Teacher@chemteacherphil was found, this channel is primarily focused on educational and tutorial style chemistry videos, it was also realized that he also uses different application to share the same video content, the followers of each of his platforms were compared finding that in TikTok he has 3.2M followers. (see table 3 and graph 4)

Table 3: Phillip Cook followers in different applications

Phillip Cook chemteacherphil

Application Followers

$\begin{array}{ll}\text { Twitter } & 2106 \\ \text { YouTube Chanel } & 5000 \\ \text { Instagram } & 74500 \\ \text { TikTok } & 3200000\end{array}$

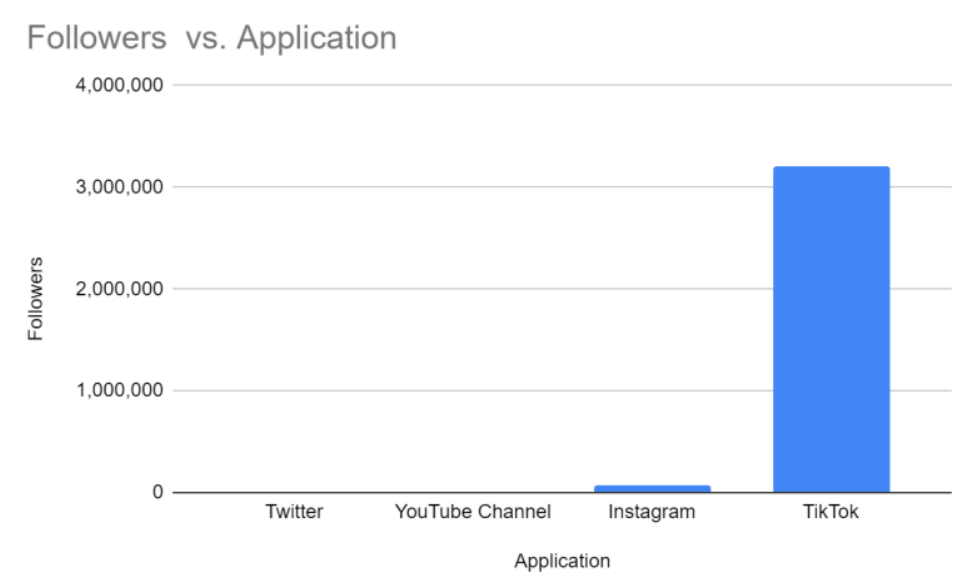

Graph 4: Comparison of followers of Philip Cook in different applications with the same video content

Once all this information was analyzed, the final idea was to design two fun activities for the students to do at home and to comply with showing a chemical phenomenon and instead of making a written report they were asked to make a video using the TikTok tool to present the conclusions and explanation of the observed phenomena of the experiments with a one minute video. 


\section{Objectives}

The main purpose is to motivate students to want to learn about inorganic chemistry. Include in the planning activities that are innovative and that encourage motivation in the students of the PrepaTec Campus Morelia.

\section{Objectives of the project}

- To Promote self-management skills

- To Encourage the use of technology in Chemistry class

- To Motivated students to learn and enjoy studying Chemistry

\section{Methodology}

- Publish Lab Instructions and procedures LMS Canvas on a Monday in order for the students to start gathering all the materials needed

- Schedule an asynchronous class for students to work of their experiment and film it

- They have two days to submit their video to LMS CANVAS assignment

- Grade Video and give student feedback (see table 4)

Table 4: Video Checklist

Elements Points

Title

Background Music

5

Hashtag \#PrepaTec

Duration: 1 minute

Explanation of activity

Explanation of Phenomenon

Conclusion

Sound and diction

Student clearly visible 
The two activities that were chosen were:

- Lab 1; Intermolecular Forces: Magic Trick, Surface tension is a force that can prevent water from spilling out of an open jar when it is turned upside down.

- Lab 2: Hot Ice from Bicarbonate of Sodium: Mixing baking soda and vinegar to make sodium acetate, known as hot ice because the ice form is hot to the touch.

\section{Results}

In the satisfaction survey that was applied to the 129 students, at the end of the semester AugustDecember 2020, on "Did you like the new format of the chemistry labs using Tiktok app?", on a scale likert from 1 to 5 where ( 1 is very satisfactory and 5 unsatisfactory). Grades of 4.76 were obtained with a standard deviation of 0.28 . The main purpose is to motivate students to learn about inorganic chemistry, including the planning activities that are innovative and that encourage the students,

Unfortunately we did not make a comparison to compare if there is any improvement in academic achievement by delivering the lab report using the TikTok application, for further research it will be important to do so.

\section{Conclusion}

At the end of the activity we could see that the students have a lot of imagination and creativity to do their videos, it should also be noted that in combination with the TikTol application they used other video editing tools such as Apple Imovie, Inshot, Rush, Magistro among others before uploading the final video to TikTok. The students also were capable of explaining the experiment and the result and conclusion in one minute video while enjoying the process and this helped them to develop critical thinking and metacognition.

I truly believe that TikTok is a tool that has great potential to be used in the classroom in any area of knowledge.

\section{Acknowledgments}

"The author would like to acknowledge the financial support of Writing Lab, Institute for the Future of Education, Technologico de Monterrey, Mexico, in the production of this work."

\section{References}

Anderson, K. E. (2020). Getting acquainted with social networks and apps: it is time to talk about TikTok. Library $\mathrm{Hi}$ Tech News. Retrieved May 10, 2021 from: https://www.emerald.com/insight/content/doi/10.1108/LHTN-01-2020-0001/full/html

Barrio, A. y Ruíz, I. (2014). Los adolescentes y el uso de las redes sociales. International Journal of Development and Educational Psychology. 3 (1), 571-576. Retrieved May 10, 2021 from: https://www.redalyc.org/pdf/3498/349851785056.pdf

Miles, J. (2013). Instagram power. McGraw-Hill Publishing. Retrieved May 13, 2021 from; http://videoplus.vo.llnwd.net/o23/digitalsuccess/SUCCESS\%20Book\%20Summaries/2014\%20March $\% 20$ SBS/InstagramPower_Review.pdf 
Moron, J., López, F. y Cobos, D. (2017). El uso de las redes sociales en educación para la salud: Una experiencia de empoderamiento social en Nicaragua. Revista de currículum y formación del profesorado. 21 (4), 429-457. Retrieved May 11, 2021 from https://www.redalyc.org/pdf/567/56754639023.pdf

Pantoja, F. (2020). El uso de TikTok en el aula para el manejo de emociones. Observatorio de innovación educativa. Retrieved May 10, 2021 from: https://observatorio.tec.mx/edu-bitsblog/tiktok-en-el-aula-manejo-de-emociones

Phillip Cook (@chemteacherphil) Official TikTok | Watch Phillip Cook.. Retrieved May 13, 2021, from: https://www.tiktok.com/@ chemteacherphil?lang=en

Ponce_Cincire (2021, January 22). El laboratorio de ciencias en casa. Observatorio de Innovación Educativa Retrieved May 13, 2021, from https://observatorio.tec.mx/edu-bits-blog/el-laboratorio-deciencias-en-casa

Model Tec21(2020)| Tecnológico de Monterrey. Retrieved May 11, 2021, from: https://tec.mx/en/model-tec21

MDF. Modelo Flexible y Digital (2020) - Innovación Educativa | Tecnológico de Monterrey. Retrieved May 11, 2021, from https://innovacioneducativa.tec.mx/transforma-flexible-draft/modeloflexible-digital/ 